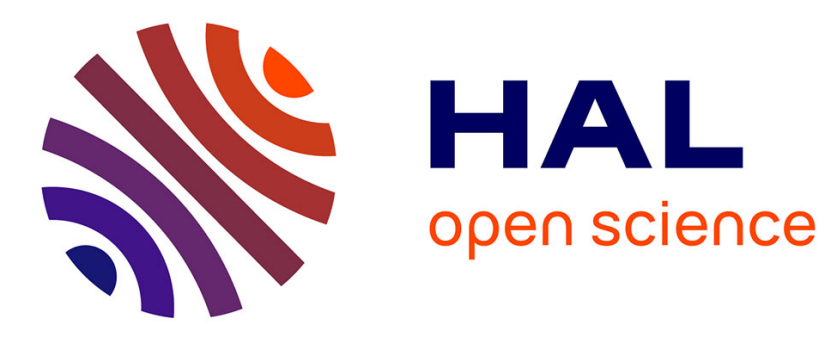

\title{
Clinical management of renal artery fibromuscular dysplasia
}

Alessandra Giavarini, Sébastien Savard, Marc Sapoval, Pierre-François Plouin, Olivier Steichen

\section{- To cite this version:}

Alessandra Giavarini, Sébastien Savard, Marc Sapoval, Pierre-François Plouin, Olivier Steichen. Clinical management of renal artery fibromuscular dysplasia. Journal of Hypertension, 2014, 32 (12), pp.2433-2438. 10.1097/HJH.0000000000000349 . hal-02503400

\section{HAL Id: hal-02503400 https: / hal.sorbonne-universite.fr/hal-02503400}

Submitted on 9 Mar 2020

HAL is a multi-disciplinary open access archive for the deposit and dissemination of scientific research documents, whether they are published or not. The documents may come from teaching and research institutions in France or abroad, or from public or private research centers.
L'archive ouverte pluridisciplinaire HAL, est destinée au dépôt et à la diffusion de documents scientifiques de niveau recherche, publiés ou non, émanant des établissements d'enseignement et de recherche français ou étrangers, des laboratoires publics ou privés. 
Clinical management of renal artery fibromuscular dysplasia: temporal trends and outcomes

Alessandra Giavarini ${ }^{1}$, Sébastien Savard ${ }^{1,2}$, Marc Sapoval $^{3,4}$, Pierre-François Plouin ${ }^{1,4}$, Olivier Steichen $^{5,6,7}$

${ }^{1}$ Assistance Publique-Hôpitaux de Paris, Hôpital Européen Georges Pompidou, Hypertension Unit, Paris, Paris, F-75015, France;

${ }^{2}$ CHU de Québec, l'Hôtel-Dieu de Québec Hospital, Nephrology Unit, Québec, Canada;

${ }^{3}$ Assistance Publique-Hôpitaux de Paris, Hôpital Européen Georges Pompidou, Department of Vascular Radiology, Paris, F-75015, France;

${ }^{4}$ Université Paris-Descartes, Faculté de Médecine, Paris, F-75006, France;

${ }^{5}$ Assistance Publique-Hôpitaux de Paris, Hôpital Tenon, Department of Internal Medicine, Paris, F75020, France;

${ }^{6}$ Sorbonne Universités, UPMC Univ Paris 06, Faculté de médecine, F-75013, Paris, France;

${ }^{7}$ INSERM, UMR_S1142, Laboratoire d'Informatique Médicale et Ingénierie des Connaissances pour la e-Santé, F-75005, Paris, France.

Corresponding author and reprint requests: PF Plouin, Hypertension Unit, Hôpital Européen Georges Pompidou, 20 rue Leblanc, 75908 Paris cedex 15, France

Tel 01560937 73, Fax 331560937 91, E-mail: pierre-francois.plouin@egp.aphp.fr

\section{Conflicts of interest: NONE}

Word count with Abstract, title page and references: 3568; text without references: 2406.

$\mathrm{N}^{\circ}$ of tables: 3. $\mathrm{N}^{\circ}$ of figures: 2 . Online supplement: 2 tables.

The Journal Subject Codes [193] [14] [17] [27] [35] 


\begin{abstract}
Objectives Renal artery fibromuscular dysplasia (FMD) is a heterogeneous condition with a broad and evolving phenotypic and angiographic spectrum. We documented therapeutic management in patients with renal artery FMD, by analyzing the medical records of hypertensive patients diagnosed with FMD at a single referral center from 1986 to 2012.
\end{abstract}

Methods Characteristics at presentation, treatments and outcomes were compared between patients diagnosed with FMD before and after the year 2000. Characteristics at presentation and outcomes were compared between patients managed conservatively, by angioplasty or surgery.

Results Patients seen since $2000(n=278)$ were older, had lower blood pressure (BP) levels and were more often managed conservatively than those diagnosed before $2000(n=134)$.

Revascularized patients had more often focal FMD and were more often males, diagnosed with hypertension and FMD at a younger age, had higher BP levels and a higher prevalence of renal asymmetry or infarction than patients treated conservatively. At the most recent visit, BP was below $140 / 90 \mathrm{mmHg}$ in two thirds of patients, in all treatment groups. Multifocal FMD was managed conservatively in $60 \%$ of cases (older patients, less severe hypertension) with similar BP outcome compared to revascularization, even after adjustment for potential confounding factors.

Conclusions The trends towards the diagnosis of FMD in older patients with less severe hypertension underscores the need for a careful selection of patients who might benefit from revascularization. This is especially true for multifocal FMD, that might be adequately managed by medication in a substantial number of cases.

\title{
Condensed Abstract
}

Patients with FMD are a heterogeneous population whose management requires individualized decisions by a multidisciplinary team. Revascularization for FMD is performed in about $50 \%$ of patients, including most of those with focal lesions. However, median age at FMD diagnosis has increased since 2000 as well as the proportion of patients treated conservatively. In adequately selected patients, medical treatment improves BP control as well as revascularization. 


\section{Key words}

Fibromuscular dysplasia; Renal artery obstruction; Balloon angioplasty; Vascular surgical procedures; Outcomes assessment 


\section{Introduction}

Fibromuscular dysplasia (FMD) is a group of idiopathic, segmental, primarily non-atherosclerotic diseases of the arterial wall leading to the stenosis of medium-sized arteries [1]. It is the second most frequent cause of RAS and presents with hypertension and, in some cases, impaired renal function, renal infarction or renal atrophy [1-4]. FMD is classified using pathological specimens into three main subtypes (intimal fibroplasia, medial fibroplasia and adventitial hyperplasia) [1] or by angiography into two subtypes, multifocal and focal $[4,5]$. Multifocal FMD, characterized by the classical "string of beads" appearance, is the angiographic presentation of medial fibromuscular dysplasia and is more frequent than focal FMD $[4,5]$.

Recent guidelines recommend renal artery revascularization for patients with FMD and recent-onset grade 2 or 3 hypertension, for patients with resistant hypertension or reporting intolerance to antihypertensive medication and in case of biochemical or imaging evidence of kidney damage [6]. For patients requiring revascularization, percutaneous transluminal angioplasty is considered the first-line option, surgery being reserved for patients with complex arterial anatomy or angioplasty failure [6, 7]. However, these guidelines for management are underpinned by only low-level evidence (small case series).

We retrospectively compared characteristics at presentation and blood pressure (BP) outcome between patients with appropriately ascertained renal artery FMD managed conservatively and those managed by angioplasty or surgery in our institution since 1986.

\section{Methods}

\section{Patients}

We reviewed the medical records of all hypertensive patients diagnosed with FMD from January 1986 to December 2012 at a reference center for FMD. As previously described [4, 8], a diagnosis of FMD was accepted for patients with non-atherosclerotic stenosing lesions affecting the trunk or branches of the renal arteries in the absence of aortic wall thickening or biochemical evidence of inflammation and in the absence of known syndromic arterial disease.

\section{Definitions}


As the vast majority of our patients did not undergo surgery, we did not use the pathological classification of FMD. The classification of FMD as focal (presence of a single stenosis on a given vessel, regardless of its length) or multifocal (presence of two or more stenoses on a given vessel segment, usually with the "string-of-beads" appearance) was based on computed tomography angiography, magnetic resonance angiography or catheter-based angiography.

The baseline visit was the diagnostic one or the first visit to our center, provided that it occurred within one year of diagnosis elsewhere, without intercurrent revascularization. Follow-up data were retained if the last visit occurred at least one month after the baseline visit.

Office BP was determined as the mean of three consecutive measurements obtained by a nurse after five minutes of rest in the sitting position, as previously reported [9]. Target BP was a systolic BP $<140 \mathrm{mmHg}$ and a diastolic BP <90 mmHg. In revascularized patients, hypertension cure was defined as target BP in the absence of antihypertensive treatment.

Creatinine clearance $(\mathrm{CCl})$ was estimated with the Cockcroft-Gault formula normalized for body surface area, because most creatinine determinations were not calibrated by isotope dilution mass spectrometry (ruling out the CKD-EPI [Chronic Kidney Disease-Epidemiology Collaboration] equation) and because most patients with renal artery FMD had a glomerular filtration rate > 60 $\mathrm{ml} / \mathrm{min} / 1.73 \mathrm{~m}^{2}$ (ruling out the MDRD [Modification of Diet in Renal Disease] equation) [10]. Renal morphologic complications were defined as infarctions (detected on ultrasound or slice imaging) or kidney asymmetry, defined as a difference of more than $20 \mathrm{~mm}$ in bipolar length between the two kidneys on ultrasound imaging.

Management was decided after evaluation of clinical and imaging data at weekly multidisciplinary meetings involving hypertension specialists, interventional radiologists and vascular surgeons. As recommended by French guidelines [11] and an expert consensus [6], revascularization was favored over medical treatment in case of: young age or recent onset of hypertension; treatment failure defined as drug resistance or intolerance; focal FMD [4]; high degree of stenosis estimated from computed tomography or magnetic resonance angiography; down-stream reduction in kidney size; and patient's preference.

\section{Statistics}


We compared characteristics at presentation, treatment and outcome between patients diagnosed with FMD before and after the year 2000. We also compared characteristics at presentation and outcomes between patients who had conservative management (no treatment or antihypertensive medication only), angioplasty or surgery. Patients who underwent both angioplasty and surgery were included in the surgery group. Since medical treatment alone is rarely used in patients with focal FMD, we also performed analyses restricted to patients with multifocal FMD, in whom revascularization and medical treatment are both viable options.

Continuous variables are presented as medians [interquartile range] and compared with the KruskalWallis or the Mann-Whitney test for unpaired data and the Wilcoxon signed-rank test for paired data. Binary variables are reported as numbers (\%) and compared with Fisher's exact test. Comparisons of treatment outcomes among patients with multifocal FMD are adjusted for the following potential confounding factors with analysis of covariance: ages at FMD diagnosis and follow-up visit; sex; bilateral RAS; baseline BP level, treatment score and BMI. Differences are considered statistically significant if $\mathrm{p}<0.05$.

\section{Results}

From 1986 to 2012, 412 hypertensive patients were diagnosed with FMD at our unit: 134 (33\%) were diagnosed before 2000 and 278 thereafter (67\%) (Figure 1). In 201 (49\%) patients, BP was adequately controlled with antihypertensive drugs, FMD lesions had no apparent impact on kidney function or size; revascularization was therefore not undertaken. Invasive interventions were performed in the remaining $211(51 \%)$ patients (Figure 2).

\section{Temporal trends}

Patients diagnosed with FMD before 2000 were younger, had more severe hypertension and were more often treated by surgery than those diagnosed since 2000 (Table 1). As the diagnostic threshold and target BP were higher before 1993 (JNC-V), we compared patients diagnosed before 1993 ( $n=56)$ with those diagnosed between 1993 and $1999(n=78)$, to explore the effect of this potential confounding factor. The patients diagnosed before 1993 had significantly higher BP values (median 172/109 mmHg vs. 162/100 mmHg; $\mathrm{p}=0.004 / 0.006$ ) and were on fewer medication (median 1 vs. $2 ; \mathrm{p}<0.001$ ). Nevertheless, BP remained significantly higher in patients diagnosed 
between 1993 and 2000 than in those diagnosed after $2000(162 / 100 \mathrm{mmHg}$ vs. $144 / 87 \mathrm{mmHg}$; p < 0.001 ), despite similar treatment scores ( 2 vs. $2 ; \mathrm{p}=0.33$ ). This confirms a temporal trend towards lower BP at FMD diagnosis, at least partly independent of the lower BP goals.

\section{Interventions}

Angioplasty was performed in 177 (43\%) patients, 58 (33\%) of whom had at least one subsequent endovascular intervention on the same side or on both sides during follow-up. Surgery was the firstchoice option in 23 patients and was carried out after one or more attempts at angioplasty in another 11 patients. In the latter 11 cases complex stenosis, such as occlusion, long/tight stenosis or branch involvement were the most frequent reasons for subsequent surgery. For the 41 kidneys operated (including bilateral treatment in seven cases), aortorenal bypass was the most common intervention $(n=24)$, followed by nephrectomy $(n=9)$, autologous renal transplantation $(n=5)$ and ex situ repair $(n=3)$.

Characteristics at presentation differed markedly between patients treated conservatively and patients treated by surgery or angioplasty (Table 2). Almost all patients treated conservatively had multifocal FMD, partly explaining older age, higher body mass index, more frequent dyslipidemia and lower blood pressure. However, when the comparison was restricted to patients with multifocal FMD, conservative treatment was still chosen in older patients, with a longer history of hypertension and lower baseline BP values (see Supplemental Table 1, Digital Content, illustrating baseline characteristics, by treatment option).

\section{Outcome by treatment}

Fourty-four $(11 \%)$ patients had been referred from a distant area for the confirmation of diagnosis or therapeutic management and could not be followed up. For the 330 patients attending both baseline and follow-up visits at our unit (80\%), follow-up was longer for those who underwent surgery, because most of the interventions on these patients were carried out before 2000. Baseline $\mathrm{BP}$ was higher, but the decrease in BP larger in patients who underwent angioplasty or surgery that in those treated conservatively. As a result, target BP was reached in two thirds of patients at the most recent visit in all three treatment groups. Renal morphologic complications (kidney length asymmetry, renal infarction) were more frequent in patients who had undergone revascularization 
than in those treated conservatively but there was no correlation between morphological complications and $\mathrm{CCl} \leq 60 \mathrm{ml} / \mathrm{min} / 1.73 \mathrm{~m}^{2}$ at follow-up (data not shown). Only one patient had a $\mathrm{CCl} \leq 30 \mathrm{ml} / \mathrm{min} / 1.73 \mathrm{~m}^{2}$ at the last follow-up (in the medical treatment group).

The analyses of treatment outcomes restricted to patients with multifocal FMD had comparable results (see Supplemental Table 2, Digital Content, showing BP and renal outcome at most recent visit by treatment option). Most notably, BP pressure at follow-up was similar in those treated conservatively and those revascularized, even after adjusting for potential confounding factors (ages at FMD diagnosis and follow-up visit; sex; bilateral RAS; baseline BP level, treatment score and BMI).

\section{Discussion}

This large series of hypertensive patients with renal artery FMD shows that more cases per year have been diagnosed recently than before 2000, that revascularization was carried out in half the cases (less frequently in recent years) and that treatment was tailored to clearly different clinical profiles. At the most recent follow-up visit, only a minority of revascularized patients was cured, but target BP was met in two thirds of patients, regardless of treatment group.

\section{Temporal trends}

The observed increase in the number of FMD in recent years may reflect a referral bias, as a national reference center for FMD was established within our unit in 2007. However, a gradual increase in the recruitment of subjects with renal artery FMD became evident long before 2007 (Figure 1). One probable explanation is the wider use of noninvasive angiography, resulting in the detection of incidental FMD lesions in patients with essential hypertension. Accordingly, the patients diagnosed with FMD after 2000 have lower BP levels than those diagnosed before 2000, and this difference is not fully explained by a more stringent definition of hypertension since the early 1990s. In parallel, we observed a time-dependent increase in the use of medical treatment alone for these patients with a milder clinical phenotype. 
In this cohort, $97 \%$ of the patients managed conservatively had multifocal FMD. A cautious approach is justified in the management of patients with multifocal FMD, because they are generally older, have less severe hypertension than those with focal FMD $[4,12]$ and they may have non hemodynamically significant FMD lesions. The "string-of-beads" pattern hinders the quantification of RAS even with catheter angiography $[2,4,13]$. The decision to revascularise could be improved by intravascular ultrasound, optical coherence tomography or the assessment of flow fractional reserve, but these procedures have not been investigated in FMD. Our results suggests that medical treatment alone is as effective as revascularization in patients with multifocal FMD properly selected by a multidisciplinary team.

By contrast, patients with focal FMD are generally younger and have more severe hypertension [4, 12]; focal FMD is more easy to quantify, commonly decreases luminal diameter by $75 \%$ or more and is frequently associated with a small kidney on the same side [12]; finally, BP is reduced to a larger extent by revascularization in patients with focal FMD than in those with multifocal FMD [4].

At the most recent visit, BP decrease was greater in patients who had undergone revascularization than in those treated conservatively. However, it is not possible to conclude that revascularization is more effective than conservative management because there were large differences in baseline characteristics, including BP levels, between the three treatment groups. On the opposite, our comparisons adjusted on potential confounder suggest that medical treatment might be as effective as revascularization in multifocal FMD.

\section{Limitations and strengths}

Our study has a number of limitations. It is retrospective, but individual patient data were recorded prospectively. We used noninvasive angiography in most of our patients and stenosis grade was therefore hard to quantify. The distribution of patients between the three treatment groups reflects physician choice and resulted in different patient profiles in the different groups, in compliance with current recommendations [6]. Outcomes were assessed in terms of BP and renal function, which are surrogate endpoints. However, these surrogates are strongly associated with the risk of clinical cardiovascular or renal events, which are rare in a population mostly composed by middle-aged women. 
Only two previous series, published in the 1980s, have described treatment options in patients with renal artery FMD $[14,15]$. They retrospectively reported the BP outcome of angioplasty in 31 and 18 patients and of surgery in 33 and 22 patients, respectively. Hypertension cure, defined as a systolic BP < $160 \mathrm{mmHg}$ in one report [14] and < $150 \mathrm{mmHg}$ in the other [15], was observed in $34 \%$ and $51 \%$ of revascularised patients, respectively. Assessment of BP outcome was not adjusted on baseline characteristics. Our study includes a much larger number of hypertensive patients with FMD, carefully assessed by a team of hypertension specialists, vascular surgeons and interventional radiologists experienced in the diagnosis and management of this condition. We used angiographic imaging to investigate arterial lesions, ensuring a high specificity of FMD diagnosis and subtype classification. We performed multivariate adjustment to compare outcomes of different treatment strategies, including medical treatment alone, among patients with multifocal FMD.

\section{Clinical implications}

According to the American College of Cardiology/American Heart Association (ACC/AHA) practice guidelines, RAS of more than 50 to $70 \%$ in a hypertensive patient with FDM is considered symptomatic and amenable to revascularization [16]. This recommendation is also endorsed by the European Society of Cardiology [17]. Recent guidelines focusing on FMD are more conservative [6]. They state that, in hypertensive patients with FMD-related RAS "the therapeutic decision should take into account the symptomatology, the nature and localization of the lesions, the experience of the center, as well as the age and preferences of the patient" (Class I, level of evidence $\mathrm{C}$ ). Our results confirm that conservative management is a reasonable alternative in appropriately selected patients.

In conclusion, patients with FMD differ in age, hypertension severity and angiographic phenotype. They require personalized care provided by a multidisciplinary team of experienced experts. Age has increased and BP decreased at FMD diagnosis since 2000. Revascularization for FMD is still performed in most patients with focal FMD, but medication alone provides adequate BP control in a substantial number of patients with multifocal FMD. 


\section{Acknowledgments}

We thank Drs Laurence Amar, Guillaume Bobrie, Antoine Chedid, Beatrice Fiquet, Michael Frank and Aurelien Lorthioir for their help with FMD patient recruitment and data collection. PierreFrançois Plouin is a member of the Département Hospitalo-Universitaire of the HEGP. 


\section{References}

1. Slovut DP, Olin JW. Fibromuscular dysplasia. N Engl J Med. 2004;350:1862-1871.

2. Plouin PF, Perdu J, La Batide-Alanore A, Boutouyrie P, Gimenez-Roqueplo A-P, Jeunemaitre X. Fibromuscular dysplasia. Orphanet J Rare Dis. 2007;2:28.

3. Olin JW, Froehlich J, Gu X, Bacharach JM, Eagle K, Gray BH e al. The United States registry for fibromuscular dysplasia: results in the first 447 patients. Circulation. 2012;125:3182-90.

4. Savard S, Steichen O, Azarine A, Azizi M, Jeunemaitre X, Plouin PF. Association between 2 angiographic subtypes of renal artery fibromuscular dysplasia and clinical characteristics. Circulation. 2012;126:3062-9.

5. Olin JW. Is fibromuscular dysplasia a single disease? Circulation. 2012;126:2925-7.

6. Persu A, Giavarini A, Touzé E, Januszewicz A, Sapoval M, Azizi M, Barral X, Jeunemaitre X, Morganti A, Plouin PF, de Leeuw P. On behalf of the ESH Working Group "Hypertension and the Kidney". European consensus on the diagnosis and management of fibromuscular dysplasia. J Hypertens 2014 (in press).

7. Trinquart L, Mounier-Vehier C, Sapoval M, Gagnon N, Plouin PF. Efficacy of revascularization for renal artery stenosis caused by fibromuscular dysplasia: a systematic review and meta-analysis. Hypertension. 2010;56:525-32.

8. Savard S, Azarine A, Jeunemaitre X, Azizi M, Plouin PF, Steichen O. Association of smoking with phenotype at diagnosis and vascular interventions in patients with renal artery fibromuscular dysplasia. Hypertension. 2013;61:1227-1232.

9. La Batide-Alanore A, Chatellier G, Bobrie G, Fofol I, Plouin PF. Comparison of nurse-and physician-determined clinic blood pressure levels in patients referred to a hypertension clinic: implications for subsequent management. J Hypertens. 2000;18:391-398.

10. Earley A, Miskulin D, Lamb EJ, Levey AS, Uhlig K. Estimating equations for glomerular filtration rate in the era of creatinine standardization: a systematic review. Ann Intern Med. 2012;156:785-795. 
11. Barral X, Joffre F, Mousseaux E, Persu A, Plouin PF, Touzé E et al. Dysplasie fibromusculaire symptomatique chez l'adulte. Protocole national de diagnostic et de soins. Haute Autorité de Santé [Internet]. 2010. Available from : http://www.hassante.fr/portail/upload/docs/application/pdf/201103/ald_31_pnds_dfm_web.pdf

12. Pannier-Moreau I, Grimbert P, Fiquet-Kempf B, Vuagnat A, Jeunemaitre X, Corvol P, Plouin PF. Possible familial origin of multifocal renal artery fibromuscular dysplasia. J Hypertens. 1997; 15:1797-1801.

13. WilloteauxS, Faivre-Pierret M, Moranne O, Lions C, Bruzzi J, Finot M et al. Fibromuscular dysplasia of the main renal arteries: comparison of contrastenhanced MR angiography with digital subtraction angiography. Radiology. 2006;241:922-929.

14. Lüscher T, Keller H, Imhof H, Greminger P, Kuhlmann U, Largiadèr F et al. Fibromuscular hyperplasia: extension of the disease and therapeutic outcome. Results of the University Hospital Zurich Cooperative Study on Fibromuscular Hyperplasia. Nephron. 1986;44:109-114.

15. Hägg A, Aberg H, Eriksson I, Lörelius LE, Mörlin C. Fibromuscular dysplasia of the renal artery--management and outcome. ActaChir Scand. 1987;153:15-20.

16. Hirsch AT, Haskal ZJ, Hertzer NR, Bakal CW, Creager MA, Halperin JL et al. American Association for Vascular Surgery; Society for Vascular Surgery; Society for Cardiovascular Angiography and Interventions; Society for Vascular Medicine and Biology; Society of Interventional Radiology; ACC/AHA Task Force on Practice Guidelines Writing Committee to Develop Guidelines for the Management of Patients With Peripheral Arterial Disease; American Association of Cardiovascularand Pulmonary Rehabilitation; National Heart, Lung, and Blood Institute; Society for Vascular Nursing; TransAtlantic Inter-Society Consensus; Vascular Disease Foundation. ACC/AHA 2005 Practice Guidelines for the management of patients with peripheral arterial disease (lower extremity, renal, mesenteric, and abdominal aortic): a collaborative report from the American Association for Vascular Surgery/Society for Vascular Surgery, Society for Cardiovascular Angiography and Interventions, Society for Vascular Medicine and Biology, Society of Interventional Radiology, and the ACC/AHA Task Force on Practice Guidelines (Writing Committee to Develop Guidelines for the Management of Patients With Peripheral Arterial Disease): endorsed by the American Association of Cardiovascular and Pulmonary Rehabilitation; National Heart, Lung, and Blood Institute; Society for Vascular Nursing; 
TransAtlantic Inter-Society Consensus; and Vascular Disease Foundation. Circulation. 2006;113:e463-654.

17. Tendera M, Aboyans V, Bartelink ML, Baumgartner I, Clément D, Collet JP et al. ESC Committee for Practice Guidelines. ESC Guidelines on the diagnosis and treatment of peripheral artery diseases: Document covering atherosclerotic disease of extracranial carotid and vertebral, mesenteric, renal, upper and lower extremity arteries: the Task Force on the Diagnosis and Treatment of Peripheral Artery Diseases of the European Society of Cardiology (ESC). Eur Heart J. 2011;32:2851-906. 
Figure 1. Number of patients with FMD, by year of diagnosis

This figure does not include 74 patients diagnosed with FMD from 2010 to 2012, because they do not constitue a 5-year category

Figure 2. Patients' flowchart 


\section{Supplemental Digital Content}

Supplemental Table 1. Baseline characteristics in patients with multifocal FMD, by treatment option (.doc)

Supplemental Table 2. Blood pressure and renal outcome at most recent visit in patients with multifocal FMD, by treatment option (.doc) 